\title{
MONITORING THE INDUSTRIAL SOURCES OF AEROSOL IN CUBATAO, BRAZIL, USING A SCANNING ELASTIC LIDAR AND A LIDAR DOPPLER
}

\author{
Renata F. da Costa ${ }^{1 *}$, Marcia T. A. Marques ${ }^{2}$, Fernanda de M Macedo ${ }^{2}$, Izabel da Silva Andrade ${ }^{2}$, \\ Elaine Cristina Araujo ${ }^{2}$, Thais Correa ${ }^{2}$, Maria Helena Goncalves de Andrade Salani ${ }^{2}$, Daniel Silveira \\ Lopes $^{\mathbf{3}}$, Maria Lucia Goncalves Guardani ${ }^{3}$, Eduardo Landulfo ${ }^{\mathbf{2}}$, Roberto Guardani ${ }^{\mathbf{1}}$ \\ ${ }^{1}$ University of Sao Paulo, Chemical Engineering Department, Brazil, *renata.facundes.costa@usp.br \\ ${ }^{2}$ IPEN - Energy and Nuclear Power Research Institute, Brazil \\ ${ }^{3}$ CETESB - Sao Paulo State Environmental Agency, Brazil
}

\begin{abstract}
Field campaigns with a scanning multiwavelength elastic lidar coupled with a Doppler system to monitor industrial atmospheric aerosol emissions were carried out, with the objective of monitoring aerosol emission sources and plume dispersion. Since the technique provides information on the spatial and temporal distribution of aerosol concentration, the implementation of a systematic monitoring procedure is proposed as a valuable tool in air quality monitoring applied to regions of interest.
\end{abstract}

\section{INTRODUCTION}

The area around the Brazilian city of Cubatao is known for the highly concentrated industrial activities, which, combined with the specific geographical situation, results in a series of problems related with air quality [1].

Cubatao is located in a narrow coastal plain surrounded by a steep mountain range to the north, west, and east, and by the sea to the south. In the region, there is a large oil refinery, a steel production site, a cement plant, plus a number of petrochemical and fertilizer plants, and the largest harbor in South America. At ca. $1 \mathrm{~km}$ west and northwest a 600-1000 m high mountain shell retains air circulation. Due to the local topography and proximity of the ocean, wind direction and velocity show daily changes that affect air quality, and frequent events of high pollutants concentration in the industrial area are recorded. A significant number of events of high levels of $\mathrm{PM} 2.5, \mathrm{PM} 10, \mathrm{O}_{3}, \mathrm{NO}_{2}$ and $\mathrm{SO}_{2}$, are recorded by the local authority (CETESB), which operates 5 air quality monitoring stations in the region [2].

\section{SYSTEM SETUP}

For the study presented here two lidar systems were used. A three-wavelength elastic backscatter lidar system and a Doppler lidar.

\subsection{Elastic lidar}

The three-wavelength elastic backscatter system operates with a Nd:YAG laser (CFR 450, Quantel S.A.) at $355 \mathrm{~nm}, 532 \mathrm{~nm}$, and $1064 \mathrm{~nm}$, transmitting pulses of $7 \pm 2 \mathrm{~ns}$ in duration at a fixed repetition rate of $20 \mathrm{~Hz}$ and a divergence of less than $0.3 \mathrm{mrad}$. The receiver used to collect the backscattered laser light is a $150 \mathrm{~mm}$ diameter Dall-Kirkham telescope with an effective focal length of $1000 \mathrm{~mm}$.

\subsection{Doppler Lidar}

The Doppler lidar is a pulsed lidar model Windcube V2 from Leosphere that detects the frequency shift from the backscattered light due the particles movement, the frequency shift is proportional to the line-of-sight velocity and the wind velocity and the wind direction can be inferred. The lidar was set up to measure vertical profile of wind velocities and wind direction in 12 levels from 40 to $290 \mathrm{~m}$ with a vertical resolution of 20 to $30 \mathrm{~m}$, recording 10 minutes averaging with a temporal resolution of approximately $1 \mathrm{~Hz}$. The Doppler lidar was co-located to the Elastic lidar during the measurement campaign.

\section{METHODOLOGY}

The campaigns for data collection were carried out in Cubatao during August 2016, under dry weather conditions, to monitor the spatial and temporal distribution of aerosols in the region. The lidar systems were installed in the center of 
an industrial complex where most fertilizer plants and a steel industry are located.

\subsection{Data acquisition}

For data acquisition, an elevation of 12 degrees and a window of 40 degrees in azimuthal angle were adopted. Three strategic sectors were scanned with these elevation and azimuthal angles in 1 degree steps. Each sector was scanned three times with an integration time of 5 seconds, totalizing 15 seconds for each primary data set. The first sector was facing the north direction (center in $12^{\circ} \mathrm{N}$ ), the second was facing $50^{\circ} \mathrm{NE}$, and the third and last sector was facing $100^{\circ} \mathrm{E}$, as azimuthal angle reference.

Information about wind velocity and wind direction were acquired at the same site and time with the Doppler lidar for 12 levels of measurements, 40, 60, $80,100,120,140,160$, $180,200,230,260$ and $290 \mathrm{~m}$.

\subsection{Data analysis}

In order to analyze the data, plan position indicator (PPI) plots of the range-corrected lidar backscattered signal were created for each of the three wavelengths, by interpolating the data between azimuthal angle steps.

The range-corrected lidar backscattered signal at a given distance from the system is expressed as:

$$
\text { R.C.S. }(\lambda)=\mathrm{KO}(r) \beta(\lambda) e^{-2 \int_{r_{0}}^{r} \alpha(\zeta, \lambda) \mathrm{d} \zeta}
$$

where R.C.S. $(\lambda)$ is the range corrected lidar signal for dark-current, zero-bin, background and rangesquared distance at wavelength $\lambda[3], \mathrm{K}$ is an instrumental constant accounting for the effective telescope area, pulse length and optical efficiency, $\mathrm{O}(r)$ is the overlap function, which refers to the geometrical overlap between the laser beam and the telescope field of view depending on the distance $r$ from the lidar system, $\beta(\lambda)$ is the atmospheric backscatter coefficient for both molecules and particle contributions. $\alpha(\zeta, \lambda)$ is the atmospheric extinction coefficient (molecule plus particle contribution) which depends on the wavelength and the traveling distance $\zeta$.

To improve the analysis, a study of the ratio between the $\ln$ R.C.S. signal was made using 1064 and $355 \mathrm{~nm}$, as describe in equation below:

$$
A_{\text {mod }}=-\frac{\ln (\text { R.C.S. }(1064) / \text { R.C.S. }(355))}{\ln (1064 / 355)}
$$

\section{RESULTS}

Figures 1, 2 and 3 show the R.C.S for 355, 532, $1064 \mathrm{~nm}$ signals, for sectors 1,2 and 3 respectively, in the form of PPI plots of the three sectors, overlaid to the region map. The plots show an intense signal in the third sector compared to the other two. The observed difference in signal strength for different wavelengths is an indication that there is a higher concentration of larger particles in this sector, due to the higher scatter intensity at $1064 \mathrm{~nm}$.

The interpretation of the scattered lidar data can only be carried out in combination with the Doppler lidar data for the wind field. A summary of the wind field measurements at two altitudes from ground level is shown in Figure 4 indicating that the wind was in mainly in the $\mathrm{N}$ to $\mathrm{S}$ direction. Thus, the observed aerosol plume is probably being generated in the north sector (first sector of the measurements), where the fertilizer plants are located, and transported by the wind to the south sector. The lidar system was able to detect the spatial distribution of the plume over the measurement region, as shown in Figures 1 to 3, for $1064 \mathrm{~nm}$. A similar interpretation of these data is valid for the other wavelengths, too.

Figure 5 shows the results of the Angstrom exponent modified. This variable provides an indirect relationship with the particle size. The larger the exponent, the smaller the particle size, thus the higher points of concentration of large particles become evidenced.

It can be observed from figure 6 relative humidity, measured during the acquisition period, did not change significantly, thus its effects were neglected in this analysis. These data were provided by the harbor of Santos and the instrumentations were about $1 \mathrm{~km}$ of distance from lidar. 


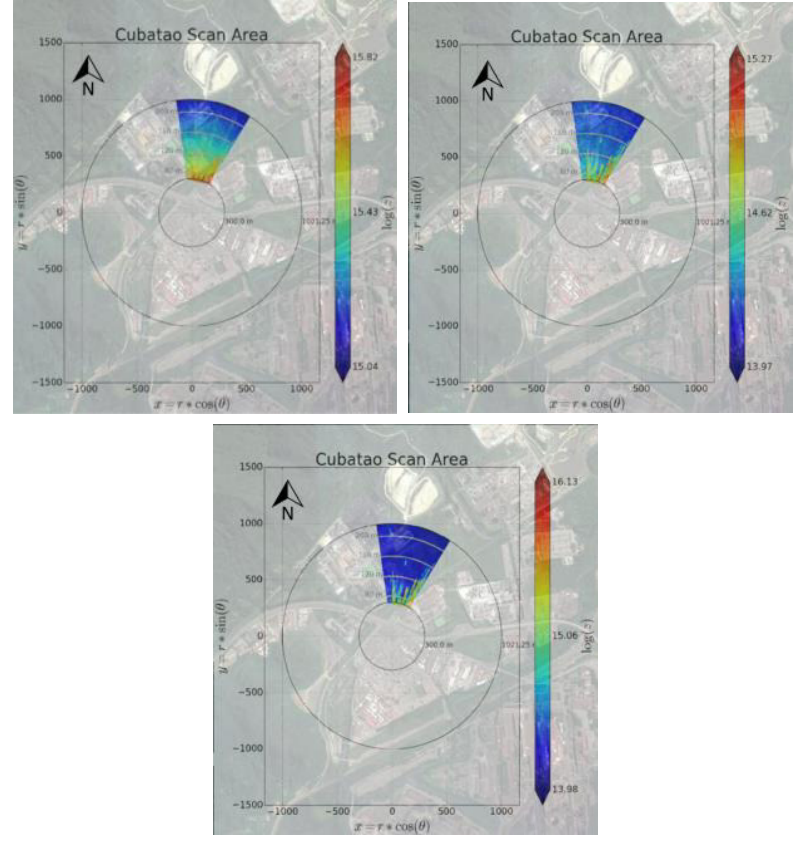

Figure 1 First sector PPI plot of $355 \mathrm{~nm}$ (left), 532 $\mathrm{nm}$ (right) and $1064 \mathrm{~nm}$ (bottom) R.C.S. Source: Google earth V 7.1.8.3036. (January 26, 2017).

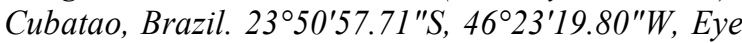
alt $6.24 \mathrm{~km} . \quad$ Digital Globe 2016. http://www.earth.google.com [January 17, 2017$].$
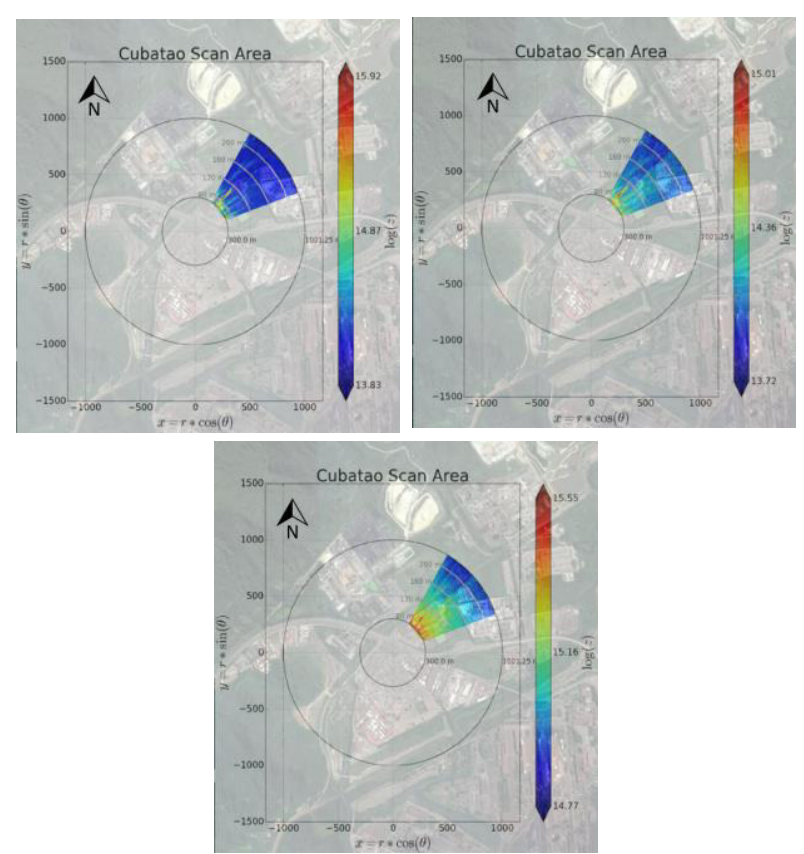

Figure 2 Second sector PPI plot of $355 \mathrm{~nm}$ (left), 532 $\mathrm{nm}$ (right) and $1064 \mathrm{~nm}$ (bottom) R.C.S. Source: Google earth V 7.1.8.3036. (January 26, 2017). Cubatao, Brazil. 2350'57.71"S, 46²3'19.80"W, Eye alt $\quad 6.24 \quad \mathrm{~km} . \quad$ Digital Globe 2016. http://www.earth.google.com [January 17, 2017].

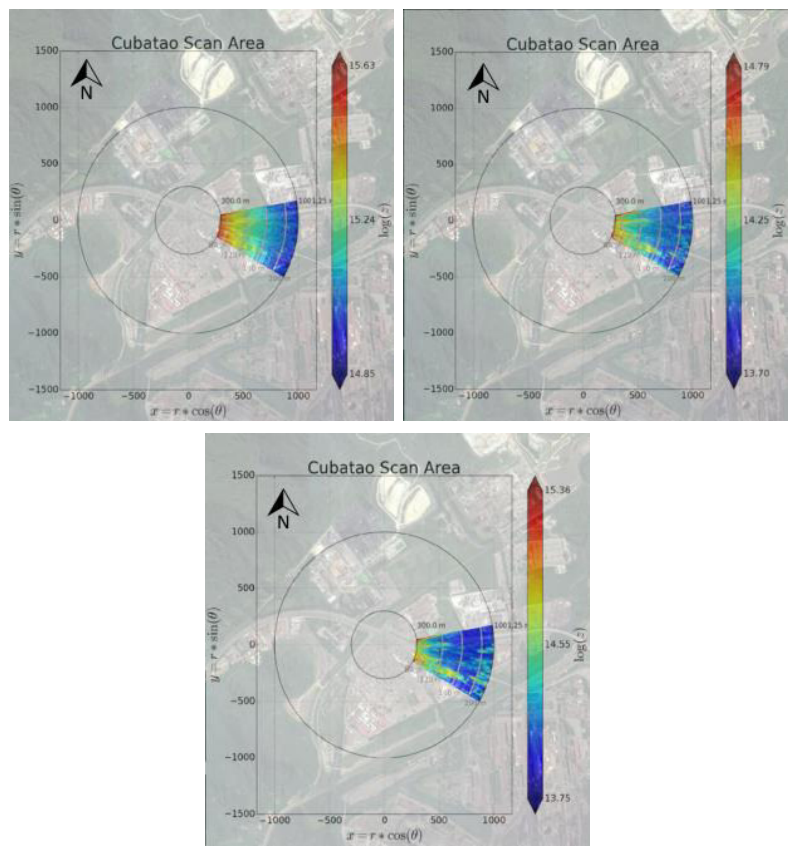

Figure 3 Third sector PPI plot of $355 \mathrm{~nm}$ (left), 532 $\mathrm{nm}$ (right) and $1064 \mathrm{~nm}$ (bottom) R.C.S. Source: Google earth V 7.1.8.3036. (January 26, 2017). Cubatao, Brazil. 2350'57.71"S, 46²3'19.80"W, Eye alt $6.24 \mathrm{~km} . \quad$ Digital Globe 2016. http://www.earth.google.com [January 17, 2017].
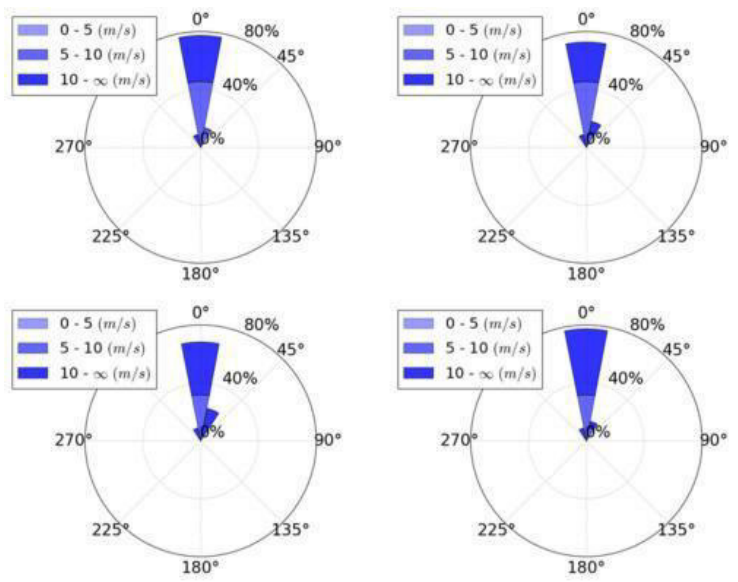

Figure 4 Wind roses indicating wind direction and wind velocity for (left to right) 80, 120, 160 and 200 $m$ 

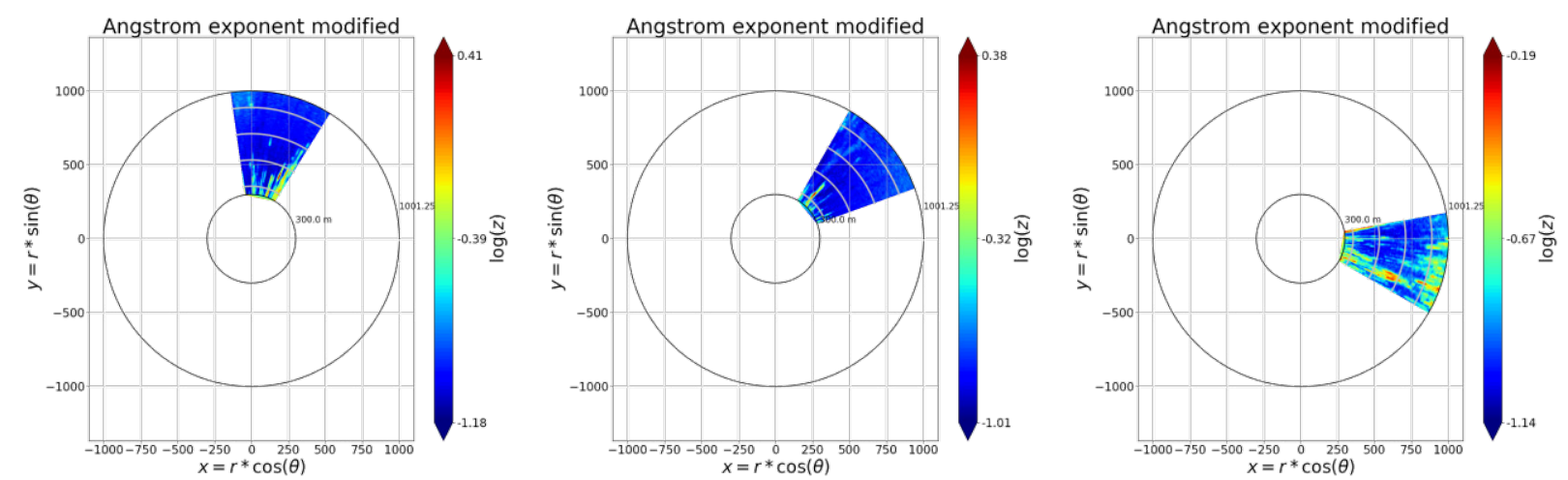

Figure 5 Angstrom exponent modified to first, second and third sector from left to right.

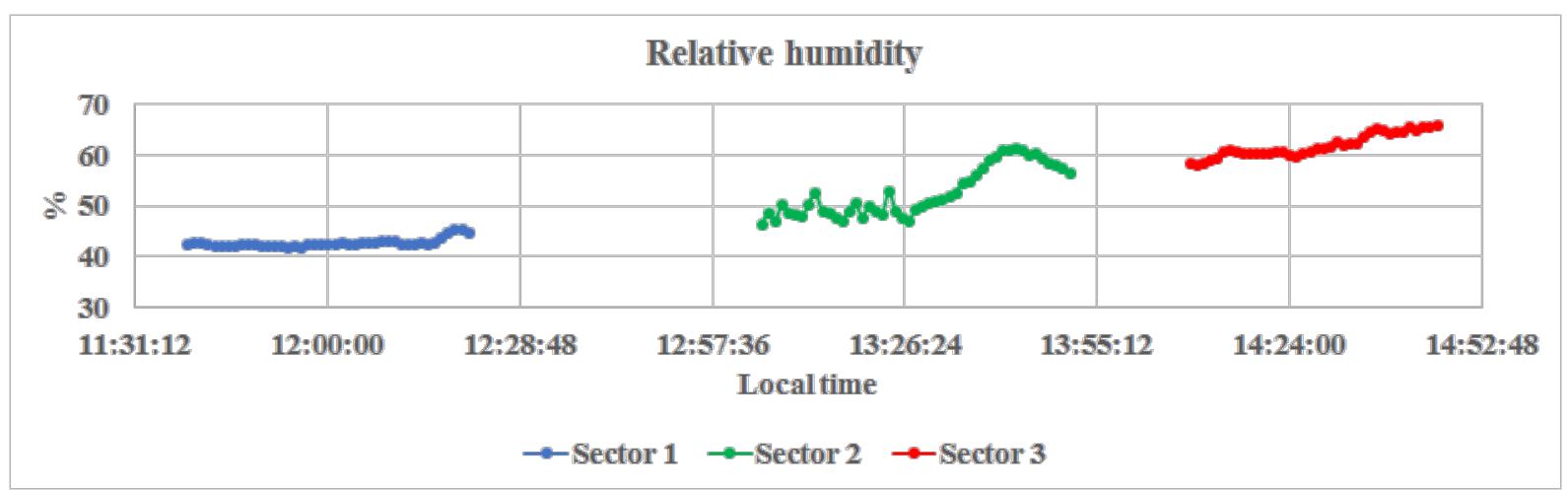

Figure 6 Relative humidity during data acquisition period.

\section{CONCLUSIONS}

Although only a small set of monitoring results is shown in this study, the results serve to illustrate the potential of the lidar technique to provide information not only on the aerosol concentration distribution over a region of interest, but also to detect specific locations where aerosols are emitted to the atmosphere, as, for instance, industrial stacks. Thus, a backscatter lidar combined with a Doppler lidar can provide real time information on the spatial distribution of aerosol concentration for different particle size ranges, enabling to identify point emission sources (stacks), or distributed sources, like resuspension, or traffic related emissions.

\section{ACKNOWLEDGEMENTS}

The authors would like to thank the supporting agencies Coordenação de Aperfeiçoamento de Pessoal de Nível Superior (CAPES), Conselho Nacional de Desenvolvimento e Pesquisa (CNPq), Fundação de Amparo à Pesquisa do Estado de São Paulo (FAPESP) and Comissão Nacional de Energia Nuclear (CNEN) for financing the research.

\section{References}

[1] Steffens J., Guardani R., Landulfo E., Moreira P. F.M. Jr. and daCosta R. F., 2011: Study on correlations between Lidar scattered light signal and air quality data in an industrial area, Proc. Environmental Sciences 4, 95-102.

[2] Da Costa, R. F., Marques, M. T. A., Lopes, D. S., Guardani, M. L. G., Macedo, F. d. M., Landulfo, E., Guardani, R., 2016: Monitoring the environmental impact of aerosol loading and dispersion from distinct industrial sources in Cubatao, Brazil, using a scanning lidar, Proc. of SPIE 10006, 1000608.

[3] Guerrero-Rascado, J. L., da Costa R. F., Bedoya, A. E., Guardani R., AladosArboledas, L., Bastidas, A. E., Landulfo E., 2014: Multispectral elastic scanning lidar for industrial flare research: characterizing the electronic subsystem and application. Optics Express 22 (25), 31063-31077. 